\title{
Rapid solidification of zirconium-based alloys
}

\author{
G K DEY and S BANERJEE \\ Metallurgy Division, Bhabha Atomic Research Centre, Bombay 400085, India
}

\begin{abstract}
Zr}$ based metal-metal binary and ternary alloys can be obtained in the amorphous state in very wide composition ranges. Several eutectic reactions and intermetallic compounds are present in these alloy systems which provide opportunities for examining the validity of different theories on glass formation. The amorphous phases in these alloys decompose by a variety of crystallization mechanisms. Instances of polymorphic, primary and eutectic crystallization have been encountered in these glasses. Zr-based metallic glasses possess excellent corrosion resistance and mechanical properties. In several studies their properties have been compared with that of their crystalline counterparts and interesting differences have emerged. In the solute lean $\mathrm{Zr}$-based alloys very large freezing ranges are available for studying the liquid to solid transformation. It has been possible to study the formation of some of the low temperature phases directly from the liquid. This paper describes some of the aforementioned studies carried out on $\mathrm{Zr}$-based amorphous and crystalline alloys.
\end{abstract}

Keywords. Rapid solidification; zirconium-based alloys.

\section{Introduction}

Zirconium-based alloys have been in use in the nuclear and chemical industries for quite some time. Considerable improvement in properties of zirconium-based alloys has been achieved by suitable modification of alloy compositions. In addition to change of alloy composition, better zirconium-based alloys can be produced by improved alloy processing techniques. In the last two decades rapid solidification has emerged as a very suitable method of alloy processing and has yielded products with superior properties. Despite this fact substantial effort has not been made in the development of rapidly solidified zirconium-based crystalline alloys. On the other hand, scientific literature abounds with reports of works on rapidly solidified noncrystalline alloys (Buschow 1984). The reasons for extensive work carried out in the field of non-crystalline zirconium-based alloys are: (i) wide composition of glass formation of the metal-metal type and (ii) interesting glass $\rightarrow$ crystal transformation modes shown by these amorphous alloys. Many of the Zr-based glasses crystallize to crystaliine phases of the same composition. These alloys provide opportunities for examining the effect of atomic arrangement alone on properties without any interference from change in chemistry of the phase (Chen 1980). A major part of this paper will therefore be devoted to description of different aspects of $\mathrm{Zr}$-based noncrystalline alloys. At the end of the paper a brief discussion about work carried out on crystalline alloys has been included.

\section{Zirconium-based metallic glasses}

Several $\mathrm{Zr}$ - TM transition metal systems have been rapidly solidified to obtain amorphous phases. $\mathrm{Zr}-\mathrm{Cu}$ system was one of the first metal-metal system in which glass formation was studied (Harmelin et al 1984). This system contains several intermetallic 
compounds and eutectic compositions. Rapid solidification has been carried out in this system and glass has been obtained in very wide composition ranges. In the $\mathrm{Zr}-\mathrm{Fe}, \mathrm{Zr}-\mathrm{Co}, \mathrm{Zr}-\mathrm{Ni}, \mathrm{Zr}-\mathrm{Be}$ and $\mathrm{Zr}-\mathrm{Cr}$ systems which have many identical features, rapid solidification has yielded amorphous phase over very large composition ranges (Tanner 1980; Buschow 1983). In some of these systems the as-solidified microstructure has been examined in detail (Tanner 1980; Dey and Banerjee 1985a). The microstructures resulting from rapid solidification of these alloys have been found to be fully amorphous or partially crystalline depending upon the cooling rate and the glass forming ability of the alloys.

\subsection{Nucleation and growth of crystals in undercooled melt of alloys}

In order to consider glass forming ability, nucleation and growth kinetics of the crystals in the undercooled melt needs to be considered. Three distinct situations of nucleation can be identified in melts subjected to undercooling:

(i) No nucleation of crystalline phase: This condition is very difficult to realize in a process like melt spinning where the cooling rate is not very high. This condition can be approached in case of very good glass forming alloys and in a process like laser glazing where the cooling rate is very high (Kavesh 1978). The steady state homogeneous nucleation frequency is quite large in Zr-based alloys (Dey 1988; Ghosh et al 1991) and hence even in a process like laser glazing, homogeneous nucleation cannot be suppressed completely. A glass produced by complete suppression of nucleation is absolutely free of quenched-in-nuclei, and is an ideal solid for studying crystallization without any interference from quenched-in-nuclei.

(ii) Limited nucleation of crystals but no growth: This condition is most readily achievable by melt spinning. Though glass is formed under this condition, the glass has quenched-in-nuclei, the nucleus density depending upon the nucleation and cooling rates. In good glass formers like $\mathrm{Zr}-\mathrm{Cu}$, it is possible to minimize the quenchedin-nucleus density by increasing the cooling rate during melt spinning for instance, by increasing the wheel speed (Kavesh 1978). The quenched-in-nuclei are very small and hence very difficult to study. In order to establish the nature of these nuclei, it is necessary to determine the atomic arrangement and their composition. This task is made difficult by the small size of the nuclei. High resolution electron microscopy can be used to determine the structure as has been done previously (Dey et al (unpublished work)). These nuclei mostly form in the early stages of nucleation, in which transient-nucleation is operative. Steady-state-nucleation occurs after transient-nucleation is over. A careful study of the nucleus size shape and density can substantially enhance the understanding of transient-nucleation. Some of the theories of transient-nucleation can be examined by this process. It was earlier believed that in a process like melt spinning transient-nucleation has no role to play. Kelton and Greer (1986) have shown that even in rapid solidification transient-nucleation period is important. During the transient nucleation stage a smaller number of nuclei are formed as compared to that expected to appear during steady-state-nucleation alone. Longer the period for transient-nucleation, better will be the glass forming ability. Transient-nucleation periods can be calculated in glass forming systems by using Kelton's approach (Kelton et al 1983). Typical transient-nucleation periods during crystallization in case of zirconium-based glass forming alloys has been 
calculated by Ghosh et al (1991) using Kelton's approach. Steady-state-nucleation follows transient-nucleation. Steady-state homogeneous nucleation frequencies can be estimated by expression due to Turnbull (1969). Using this equation and the relevant parameters for $\mathrm{Zr}$-based systems the steady-state-nucleation rate has been estimated by Ghosh et al (1991) for Zr-based glass forming alloys (Greer 1985). Steady state homogeneous nucleation frequency for $\mathrm{Zr}$-based alloys is higher than that of very good glass former like the Pd-Si alloys (Drehman and Greer 1984). In Zr-based alloys therefore homogeneous nucleation is the main barrier to glass formation.

(iii) Nucleation of a very limited number of crystals and substantial growth of these crystals: This kind of solidification leads to formation of partially crystalline ribbons. These ribbons were earlier discarded because these were found to be useless for property evaluation studies. However, these ribbons can be very useful in achieving the following objectives (Dey et al 1990):

(a) The glass forming ability of the alloy can be determined by estimating the amount of crystalline phase in the partially crystalline ribbons. Higher the amount of crystalline phase formed, lower is the glass forming ability and vice versa.

(b) By determining the identity of the crystalline phase it is possible to determine the nature of the crystalline phase competing with glass formation.

(c) By studying the morphology of the crystals it is possible to understand the process of solidification during melt spinning.

As discussed earlier, it is possible to retain glassy phase even after nucleation provided growth of crystals remains limited. Growth of crystals has been found to be of two types--diffusion limited growth and collision limited growth (Dey and Banerjee 1985). Collision limited growth rates are very high and approach the speed of sound. This kind of growth is often seen in pure metals and some alloys. Once the crystal has nucleated, growth cannot be easily suppressed in this condition. Generally diffusion limited growth rates are much slower. The reason for slow growth during diffusion limited condition are need to partition and slow rate of attachment kinetics at the crystal/liquid interface (Greer 1985). This mode of growth is more likely in glass forming solids. Study of partially crystalline ribbons in $\mathrm{Zr}$-based $\mathrm{Fe}$ and Ni bearing binary alloys has been carried out by Dey and Banerjee (1985b). These workers have identified the crystalline phases competing with glass formation in the alloys (Dey and Banerjee 1985b). The relative glass forming ability has been determined in a range of $\mathrm{Zr}-\mathrm{Ni}$ alloys by estimating the amount of crystalline phase in the partially crystalline alloys (Dey and Banerjee 1985b). The morphology of the crystals in the partially crystalline alloys has been examined by Dey and Banerjee (1985c) and Tanner (1980). Dey and Banerjee (1985c) encountered single crystals (figure 1a) and crystal aggregates (figure 1b) embedded in the amorphous matrix. Some of these aggregates have been found to show a very interesting sunflower-like morphology (figure 1b). A variety of crystal/amorphous matrix interface were encountered by these workers (Dey and Banerjee 1985c) depending upon the local conditions of solidification.

\subsection{Theoretical estimation of glass forming ability}

Numerous factors have been found to influence GFA and there is no single key parameter which can alone describe GFA. The various types of arguments put forth to 

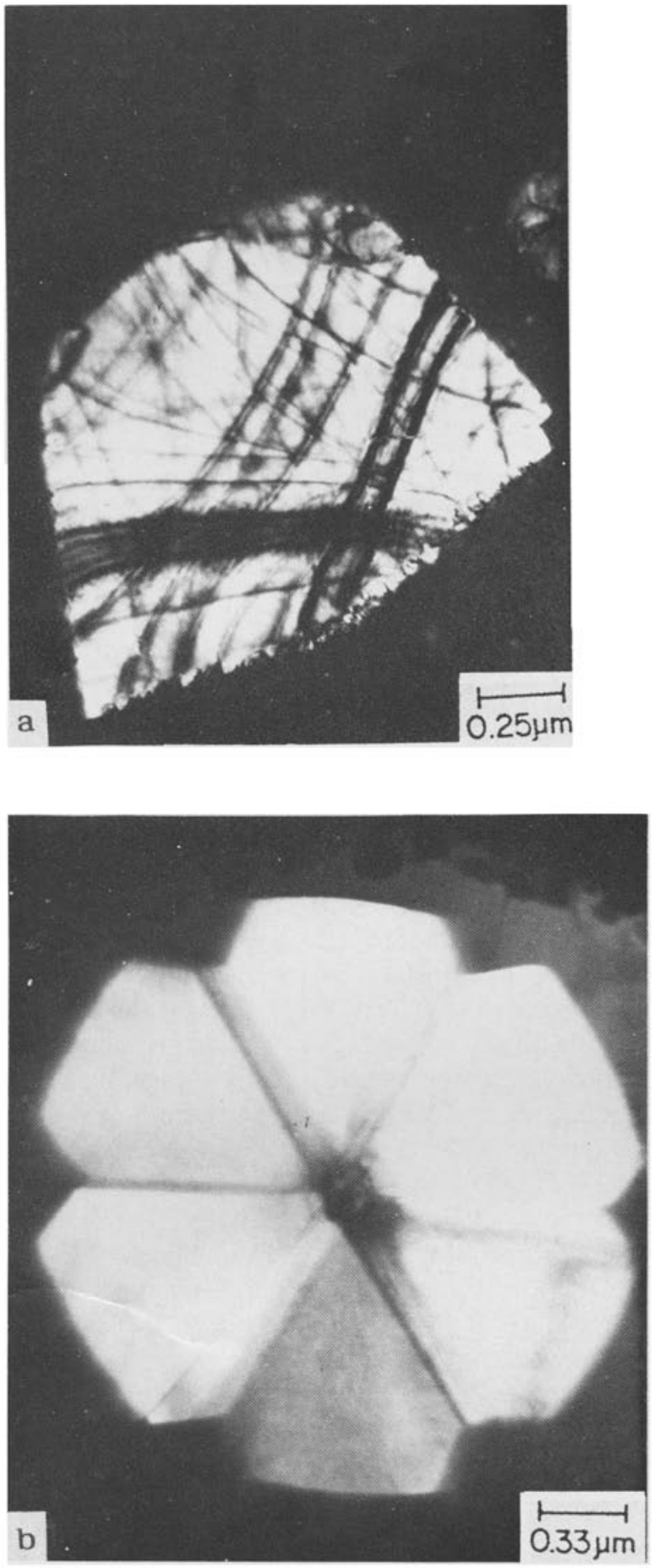

Figure 1. Bright field electron micrographs showing (a) a crystal of the $\mathrm{Zr}_{3} \mathrm{Fe}$ phase and (b) a crystal aggregate in an amorphous matrix in partially crystalline melt spun ribbon of the $\mathrm{Zr}-24 \mathrm{at}^{\circ}{ }_{11} \mathrm{Fe}$ alloy. 
explain GFA can be divided into those thermodynamic or kinetic in nature and those based on size factor and electron theory considerations. Thermodynamically glass formation is favoured in certain composition ranges of some systems where the free energy difference between the supercooled liquid and the metastable and stable phases competing with glass formation is as little as possible (Massalski 1982).

In addition to the presence of small thermodynamic force kinetic factors which suppress nucleation and growth of the competing crystalline phase, favour glass formation. It has been seen that certain ratios of atomic sizes favour glass formation particularly so whenever the atomic ratios of the base metal is more than $10 \%$ different from those of the other alloying elements (Tanner 1980). Nagel and Tauc (1975) proposed that the amorphous phase is stabilized due to a minimum in the electron density of states at the concentration where two times the Fermi wave vector $(k f)$ equal $Q_{p}$. the first peak of the structure factor (Nagel and Tauc 1975).

Phase diagrams have been found to be useful guides for determining GFA. Since $T_{g}$ is a slowly varying function of composition the interval $T_{e}-T_{g}$ where $T_{e}$ is the liquidus temperature, is the shortest at the eutectic composition (Marcus and Turnbull 1976). $T_{e}-T_{g}$ is the temperature interval in which crystallization has to be avoided for the liquid to solidify into glass. The parameter $T_{e}-T_{g}$ is normalized with respect to $T_{e}$. The normalized parameter contains the important ratio $T_{g} / T_{e}$ and the reduced glass transition temperature $T_{r g}$. Higher the value of $T_{r g}$ (which will be the case with high $T_{g}$ and low $T_{e}$ ) better is the GFA (Massalski 1975). Though $T_{g}$ is kinetic in nature $T_{e}$ is thermodynamic in origin. Lowering of $T_{e}$ alone in an eutectic region increases $T_{r g}$ and hence GFA. The various ways of assessing the extent of lowering of $T_{e}$ by alloying have been explored as a guide to GFA.

These concepts have been applied in case of $\mathrm{Zr}$-based glasses. The free energy of the liquid phase and that of the intermetallic compounds can be established by determining the free energy of different phases as a function of composition in binary alloy systems. This is possible by a thermodynamic analysis of the phase diagram incorporating some experimental thermodynamic data (Dey 1988). From the free energy hierarchy of several competing phases it could be observed that in the $\mathrm{Zr}-\mathrm{Ni}$ system, the driving force for crystal formation in $\mathrm{Zr}$-rich alloys was much smaller in case of $\mathrm{Zr}-33$ at $\% \mathrm{Ni}$ alloy as compared to that for $\mathrm{Zr}-24$ at \% $\mathrm{Ni}$ alloy (figure 2). This observation was indicative of the fact that thermodynamically glass formation tendency was higher at composition close to that of the first intermetallic compound and not the first eutectic composition.

A similar approach involving the relative free energy of the liquid and the crystalline phases uses the concept of the $T_{0}$ curve. The $T_{0}$ curve in the phase diagram is the locus of compositions at each temperature, where the liquid and the solid phases of the same composition have the same value of the integral molar free energy. The importance of the $T_{0}$ curves in connection with rapid solidification has been realized quite some time back (Aptekar and Kamenetskaya 1962). The problem of solute trapping during solidification and the importance of the $T_{0}$ in this regard has been discussed by Baker and Cahn (1971). In order to make predictions about the formation of a single solid solution after rapid solidification for a given alloy system, the position of the $T_{0}$ line in the phase diagram should be known. Dey et al (1987) and Boettinger $e^{t}$ al (1982) have examined the conditions for partitionless solidification, based on the position of $T_{0}$ curves in the phase diagram. The position of $T_{0}$ line is also extensively used in the estimation of the glass forming tendency of alloys. It has been suggested 


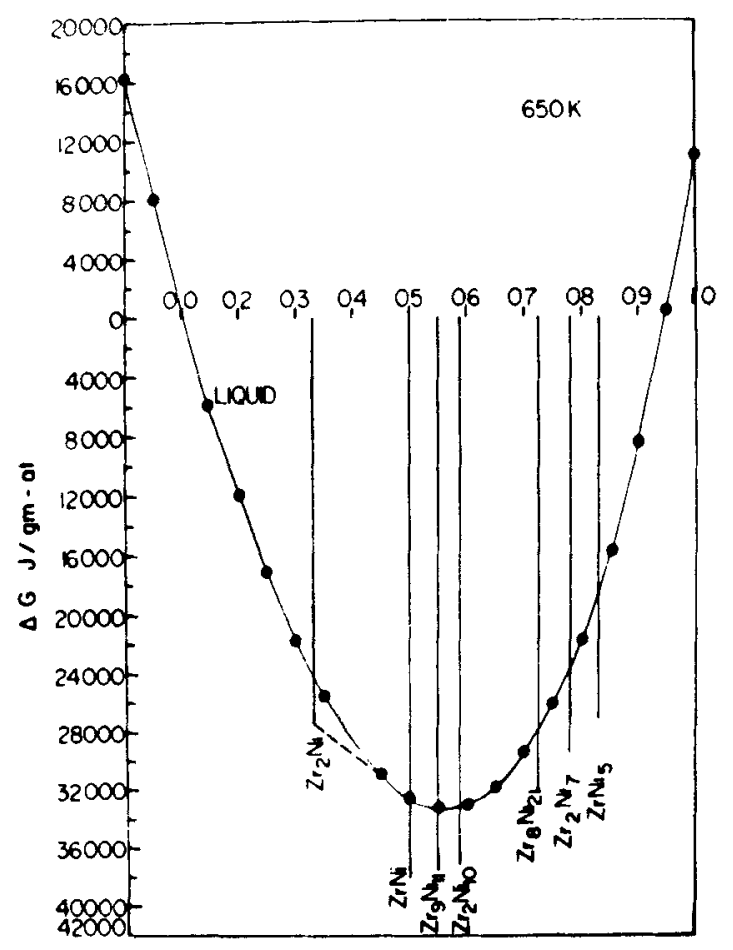

Figure 2. Diagram showing the free energy hierarchy of the liquid phase and the intermetallic compounds in the $\mathrm{Zr}-\mathrm{Ni}$ system (Dey et al 1987).

that glass formation is easier in composition ranges where $T_{0}$ temperature is depressed. In alloys having low $T_{0}$, if rapid solidification can suppress alloy partitioning, the liquid can be undercooled to such an extent that it can be vitrified. The $T_{0}$ curve determined in the $\mathrm{Zr}-\mathrm{Ni}$ system by an approach suggested by Katgerman (1983) showed that $T_{0}$ drops rapidly with increasing $\mathrm{Ni}$ content (figure 3 ) indicating that exceptionally large undercoolings will be required for formation of $\beta$ phase of the same composition as the liquid in hypereutectic compositions, a factor which will favour glass formation in these compositions.

Some of the models discussed are based on the stabilization of the liquid phase, ignoring the composition effect on the stability of the crystalline phase. There is very little evidence to substantiate the structural stabilization of the liquid even at eutectic composition. In fact, observations have been made which suggest that the viscosity of liquids and $T_{g}$ of alloy glasses are depressed, presumably due to the occurrence of atomic clustering in the region of eutectic composition. From these observations it has been concluded that it is the destabilization of the crystalline phase rather than the stabilization of the glass phase which is important (Chen 1976). Glass can be obtained in any liquid which has been so supercooled such that crystal nucleation and growth is avoided.

The overall crystal formation kinetics can be evaluated in terms of classical phase transformation kinetics theory and represented as isothermal TTT diagrams. Such diagrams were first developed by Ulhman (1974) and subsequently used by Davies (1976) to determine the value of $\dot{T}$, the critical cooling rate to just avoid crystallization. 


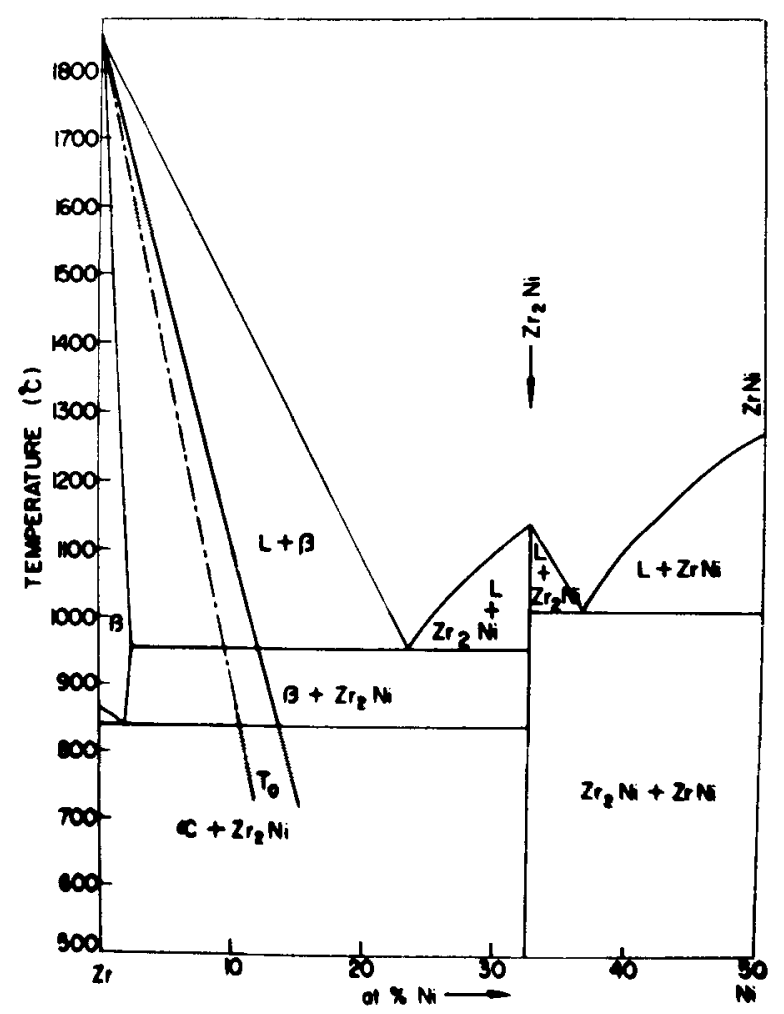

Figure 3. The liquid $/ \beta \quad T_{0}$ lines drawn on the zirconium rich side of the $\mathrm{Zr}-\mathrm{Ni}$ phase diagram. Firm line-regular solution, dotted line-ideal solution (Dey et al 1987).

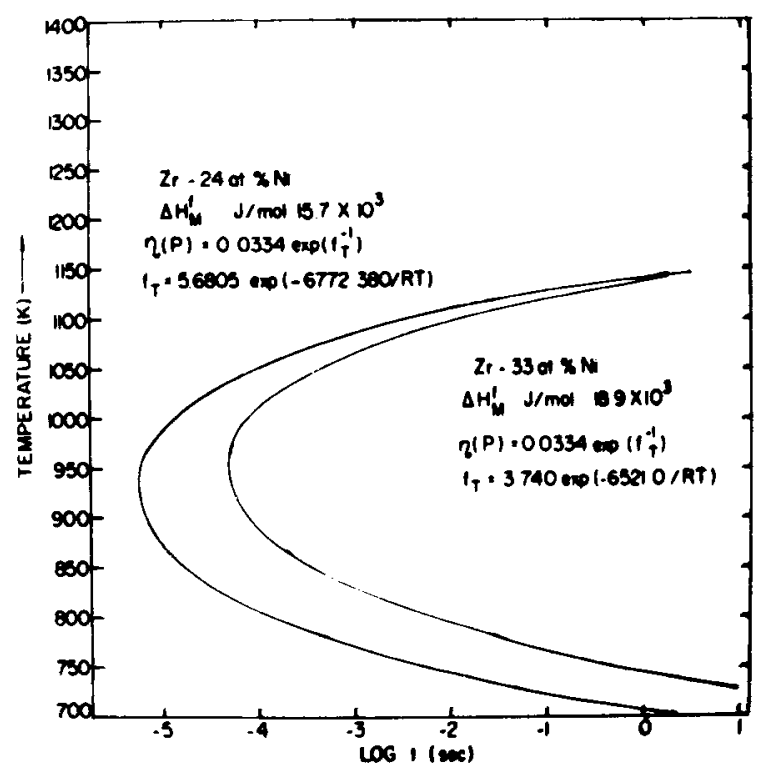

Figure 4. Theoretically generated temperature time-transformation curve for very small amount of crystal formation. The nose of the $\mathrm{T} \mathrm{T} \mathrm{T} \mathrm{curve} \mathrm{for} \mathrm{Zr}-33$ at $\% \mathrm{Ni}$ is farther away compared to that of the $\mathrm{Zr}-24 \mathrm{at} \% \mathrm{Ni}$, showing the easier glass forming ability of the former composition (Dey et al 1987). 
These TTT diagrams for two $\mathrm{Zr}-\mathrm{Ni}$ alloys, $\mathrm{Zr}-33$ at $\% \mathrm{Ni}$ and $\mathrm{Zr}-24$ at $\% \mathrm{Ni}$ are shown in figure 4 . It can be seen from these diagrams that critical cooling rate for glass formation is lower for the $\mathrm{Zr}-33 \mathrm{at} \% \mathrm{Ni}$ alloy as compared to the $\mathrm{Zr}-24 \mathrm{at} \%$ $\mathrm{Ni}$ alloy, though the latter is the eutectic composition. This estimation clearly demonstrated that the eutectic composition need not necessarily be the composition at which glass formation is the easiest. The factors of importance are the viscosity of the melt and the free energy difference between the liquid and solid phases.

\subsection{Thermal stability of Zr-based metallic glass}

$\mathrm{Zr}$-based metallic glasses show a variety of crystallization reactions. These have been studied in detail in $\mathrm{Zr}-\mathrm{Cu}, \mathrm{Zr}-\mathrm{Cr}, \mathrm{Zr}-\mathrm{Be}, \mathrm{Zr}-\mathrm{Ni}$ and $\mathrm{Zr}-\mathrm{Fe}$ systems (Tanner 1980; Buschow 1983; Dey and Banerjee 1985a; Dey 1988). Primary polymorphic and eutectic crystallization reactions have been encountered in these glasses. Studies in Zr-based ternary glasses are fewer in comparison. The overall crystallization kinetics has been studied in a number of $\mathrm{Zr}$-based binary alloys by differential scanning calorimetry (DSC). The kinetic parameter Avrami exponent, the significance of which will be discussed later has been determined in these studies. The crystal nucleation and growth kinetics have been studied separately by transmission electron microscopy (TEM) in case of $\mathrm{Zr}-33 \mathrm{Ni}$ glass by Dey (1988). This glass undergoes polymorphic crystallization. A similar study has been carried out in the amorphous alloys $\mathrm{Zr}-24$ at $\% \mathrm{Fe}$ which also undergoes polymorphic crystallization (Dey and Banerjee 1985c). Eutectic crystallization has been observed in $\mathrm{Zr}-24$ at \% $\mathrm{Ni}$ amorphous alloy (Ghosh et al 1991).

The amorphous to crystal transformation being a non-equilibrium process, can occur at any temperature where thermal fluctuation can cause atomic movements in a reasonable time frame. The rate of devitrification and the incubation periods are such that most metallic glasses can be considered to be stable indefinitely at room temperature. The often quoted crystallization temperature, $T_{x}$, is actually a function of various factors like the heating rate, the method of preparation, trapped gas, defects, impurities and the thermal history (Buschow and Beekmans 1979). However, crystallization temperature measured at a particular heating rate serves as a useful guide for comparing the relative thermal stabilities of different glasses. The temperature of crystallization has been found to be a widely varying quantity and lies between 0.4 and $0.6 T_{m}$ (where $T_{m}$ is the melting point in kelvin). In many metal-metalloid glasses crystallization temperature is a maximum near the equilibrium eutectic composition. In the compositions studied in the $\mathrm{Zr}-\mathrm{Ni}$ system, however, a monotonic increase of $T_{x}$ with increasing Ni content (from 24 to $39 \mathrm{at} \% \mathrm{Ni}$ ) has been observed despite the existence in the equilibrium diagram of two eutectic and an intermetallic compound in this composition range (Dey and Banerjee 1985b).

In order to determine the composition dependence of thermal stability of metallic glasses, thermodynamic, crystallographic and electronic factors have been considered. In many metal-metalloid glasses, the stability of the glass have been considered in terms of atomic sizes of the participating species (Walter 1981). It has been proposed by Walter (1981) that in iron-based amorphous alloys substitution of some of the iron by larger atom disturbs the close packing thereby reducing the free volumes and the diffusion coefficients. In this and some other approaches (Buschow and Beekmans 1979) it has been assumed that diffusion is the sole factor deciding the stability of 
the glass and if diffusion of the atoms is made difficult, enhanced thermal stability will result. Based on these criteria, Thompson et al (1983) chose the energy of formation of hole of the size of the smaller atom, as a parameter to gauge the rate of diffusion assuming this energy to be proportional to the activation energy of diffusion.

The crystallization of metallic glasses involves both nucleation and growth of crystals. The overall rate of transformation will therefore reflect time and temperature dependence of both these processes. Usually solid-state-nucleation and growth transformations are described by the Kolmogrov Johnson Mehl Avrami (KJMA) equation (Ghosh et al 1991).

$$
x(t)=1-\exp \left(-K t^{n}\right)
$$

where $x(t)$ is the fraction transformed after time $t, K$, the rate constant and $n$, the Avrami exponent. The KJMA equation has been modified by Thompson et al (1983) to account for simultaneous growth of quenched-in-nuclei and fresh nuclei generated during the steady-state-nucleation stage. The KJMA equation takes the following form when both the aforementioned nucleation processes are considered.

$$
x=1-\exp \left[-(\pi / 3) U^{3}\left(4 N t^{3}+I t^{4}\right)\right]
$$

where $N$, the number of quenched-in-nuclei, $U$, the growth rate and $I$, the steadystate-nucleation rate. It can be readily seen that the Avrami exponent determined by plotting $\log \{-\log (1-x)\}$ vs $\log t$ will equal 4 when the number of quenched-in-nuclei is nil $(n=0)$ and 3 when $I=0$ i.e. crystallization involves growth of quenched-in-nuclei alone (Thompson et al 1983). In cases where $n$ lies between 3 and 4 both quenched-innuclei and fresh nuclei forming during steady-state-nucleation, participate in the crystallization process. A wide range of values have been reported for the Avrami exponent. Table 1 shows typical values of Avrami exponents for different types of crystallization. The analysis of the crystallization kinetics is simpler and the value of the Avrami exponent determined, more meaningful in instances of polymorphic crystallization. Polymorphic crystallization gives a single sharp exotherm unlike primary crystallization followed by other modes. In the latter case two overlapping exotherms result (Dey et al 1986).

It has been pointed out in some recent studies that the Avrami exponent cannot be quoted as a single characteristic of the devitrification process (Calka et al 1987) because the KJMA plot is not straight and hence representing the isothermal devitrification experimental data as

$$
\frac{\Delta \ln [-\ln (1-x)]}{\Delta \ln (t)}
$$

Table 1. Avrami exponent values of different temperatures for amorphous alloys undergoing different types of crystallization.

\begin{tabular}{llcl}
\hline Type of & $\begin{array}{c}\text { Temperature of } \\
\text { crystallization } \\
(\mathrm{K})\end{array}$ & $\begin{array}{l}\text { Avrami } \\
\text { exponent }\end{array}$ \\
\hline $\mathrm{Zr}-39 \mathrm{at} \% \mathrm{Ni}$ & Primary & 699 & $2 \cdot 5$ (Dey 1988) \\
$\mathrm{Zr}-24 \mathrm{at} \% \mathrm{Fe}$ & Polymorphic & 626 & $3 \cdot 10$ (Dey and Banerjee 1985c) \\
$\mathrm{Zr}-33 \mathrm{at} \% \mathrm{Ni}$ & Polymorphic & 677 & $4 \cdot 12$ (Dey et al 1986) \\
\hline
\end{tabular}


vs $x$ plots provide a more detailed description of the crystallization process. In this modified version of the Avrami model it has been suggested that instead of having a single Avrami exponent for the entire transformation it is more appropriate to have a local Avrami exponent which describe the reactions. Some of the earlier observations on Avrami exponent have been reconsidered by this approach and a better understanding of the crystallization process has been obtained (Calka et al 1987; Dey et al (unpublished work)).

In DSC, surface crystallization has been found to influence the nature of the exotherm in the continuous heating mode as well as in the isothermal heating mode. Generally, surface crystallization always starts before bulk crystallization and manifests itself either as a separate small peak or as a shoulder to the principal peak. It is not essential that the same crystalline phase should form during surface crystallization as that forming during bulk crystallization. Occurrence of surface crystallization has been observed in some binary (Calka et al 1987) and ternary Zr-based alloys (Dey et al (unpublished work)). Identification of the products of surface crystallization has been carried out by comparing the $\mathrm{X}$-ray diffraction results on crystallized metallic glass ribbons after and before removing a layer of the material from the surface (Calka et al 1987).

\subsection{Properties}

Metallic glasses possess some unique combination of properties not observed in any other known engineering material. Almost all metallic glasses have very high strength and corrosion resistance as compared to their crystalline counterparts. Iron-based ferromagnetic metallic glasses are known to possess excellent soft magnetic properties and are finding wide scale application in transformer cores, motors and tape recorder heads. The corrosion resistance of $\mathrm{Zr}$-based amorphous alloys have been found to be superior as compared to their crystalline counterparts (Dey et al 1989). This fact has been brought out in a number of studies. The corrosion behaviour of amorphous $\mathrm{Cu}_{50} \mathrm{Zr}_{50}$ alloy has been compared with that of the crystalline $\mathrm{Cu}_{50} \mathrm{Zr}_{50}$ alloy in various alkaline, neutral and acidic media with and without chloride irons by Naka et al (1987). The effect of phosphorous on the corrosion behaviour of $\mathrm{Cu}_{60} \mathrm{Zr}_{40}$ amorphous alloys in $\mathrm{H}_{2} \mathrm{SO}_{4}, \mathrm{NaCl}$ and $\mathrm{HCl}$ solutions has been studied by Burleigh et al (1985). These workers have concluded that the presence of phosphorous enhances corrosion resistance of these amorphous alloys. Turn and Latanision (1983) have studied the influence of crystallinity on the corrosion of glassy $\mathrm{Cu}-\mathrm{Zr}$ alloys and have concluded that structure (whether crystalline or amorphous) seems generally to have a much weaker influence on anodic polarization than does alloy chemistry. Such comparative studies carried out to evaluate the effects of structure alone, however, are strictly valid only in situations where the amorphous alloys undergo polymorphic crystallization into a single crystalline phase. With this in view Dey et al (1989) have carried out studies on the corrosion behaviour of $\mathrm{Zr}_{57} \mathrm{Ni}_{33}$ amorphous alloy. This amorphous alloy undergoes polymorphic crystallization. The study by Dey et al (1989) indicated that the film formed on exposure to $1 \mathrm{~N} \mathrm{HCl}, 1 \mathrm{~N}$ $\mathrm{H}_{2} \mathrm{SO}_{4}$ and $1 \mathrm{~N} \mathrm{HNO}_{3}$ consisted of $\mathrm{ZrO}_{2}$ and $\mathrm{Zr}(\mathrm{OH})_{4}$ in the amorphous as well as in the crystalline specimens. The improved corrosion resistance of the amorphous alloy had its probable origin in the structural uniformity and the tenacity of the protective oxide film. 
Metallic glasses possess mechanical properties superior to their crystalline counterparts. Zirconium-based metallic glasses have strength and hardness values much higher than those of commercial zirconium-based crystalline alloys such as zircaloys and $\mathrm{Zr}-2.5 \mathrm{Nb}$ alloy (Douglass 1971; Dey 1988). Very extensive research has been carried out to study the flow and fracture behaviour of metal-metalloid glasses. In comparison, investigations on the deformation behaviour of metal-metal glasses has not been as extensive. The hardness of some of the titanium-based and zirconium-based metal-metal glasses has been determined by some investigators (Chen and Krause 1977; Zielinski et al 1978). Mechanical properties of $\mathrm{Zr}-\mathrm{Ni}$ partially crystalline and fully amorphous alloys have been determined by Dey and Banerjee (1985). These workers have also examined the effect of crystalline particles on flow and fracture in Zr-based metallic glasses (Dey and Banerjee 1985d).

A major part of the plastic deformation in metallic glasses is localized within the shear bands. An unequivocal description of the structure within the shear band has not yet emerged. Attempts have also been made to examine whether shear bands provide preferential sites for crystallization in samples given a heat treatment subsequent to deformation. Dey and Banerjee (1985d) concluded that crystallization proceeded at the same rate at shear bands as in regions free from bands. The structure of the shear bands has been examined by TEM in a large number of investigations (Donovan and Stobbs 1980; Dey and Banerjee 1985d). It is generally agreed that the shear band contrast observed in TEM is due to the reduced thickness of shear band regions in thin-foil specimens (Sethi et al 1978; Dey and Banerjee 1985d).

\section{Rapidly solidified crystalline alloys}

The number of studies on rapidly solidified $\mathrm{Zr}$-based crystalline alloys is small. Mention can be made of studies carried out by Banerjee and Cantor (1979) on microstructure produced in unalloyed zirconium and $\mathrm{Zr}-\mathrm{Nb}$ alloys by rapid quenching from the liquid-state. In unalloyed zirconium contaminated with $\mathrm{Si}$ and $\mathrm{O}$ the authors were able to see the formation of the $\alpha$ phase having a cellular morphology directly from the liquid phase (figure 5). In specimens containing $\mathrm{Nb}$ up to $5.5 \%$ the $\beta$ phase was found to form first from the liquid phase and then transformed to martensite (figure 6). The fine cellular structure resulting from segregation of impurities (silicon and oxygen) during the solidification process of liquid to $\beta$ was found to influence the size, distribution and structure of the martensite formed subsequently. In the $\mathrm{Zr}$ $5.5 \% \mathrm{Nb}$ alloy, free from contaminants like $\mathrm{Si}$ and $\mathrm{O}$, splat cooling resulted in the retention of the $\beta$ phase within which athermal $\omega$ particles were distributed. The shift of the $\omega$-stability region to a more dilute composition $(5.5 \%)$ from that observed $\left(7_{0}^{\circ}\right)$ in solid-state-quenched samples has been attributed to a higher concentration of vacancies. Vacancies are known to stabilize the $\omega$-like defects prior to transformation (Kuan and Sass 1976).

In another study on $\mathrm{Zr}-27 \mathrm{at}^{\circ}{ }_{0} \mathrm{Al}$ alloy Banerjee and Cahn (1983) investigated the sequence of the transformation events which lead to the formation of the $\mathrm{Zr}_{2} \mathrm{Al}$ phase $\left(B 8_{2}\right.$ structure) in this alloy. The authors have concluded from their studies that the following sequence of transformations occurred: (i) Formation of a supersaturated $\beta$ (bcc) phase by a diffusionless solidification process, (ii) spinodal clustering resulting in a composition modulation along the $\langle 100\rangle_{\beta}$ directions and (iii) formation of the $\mathrm{B} 8_{2}$ structure from the $\beta$ phase by ordering within the aluminium rich regions. 

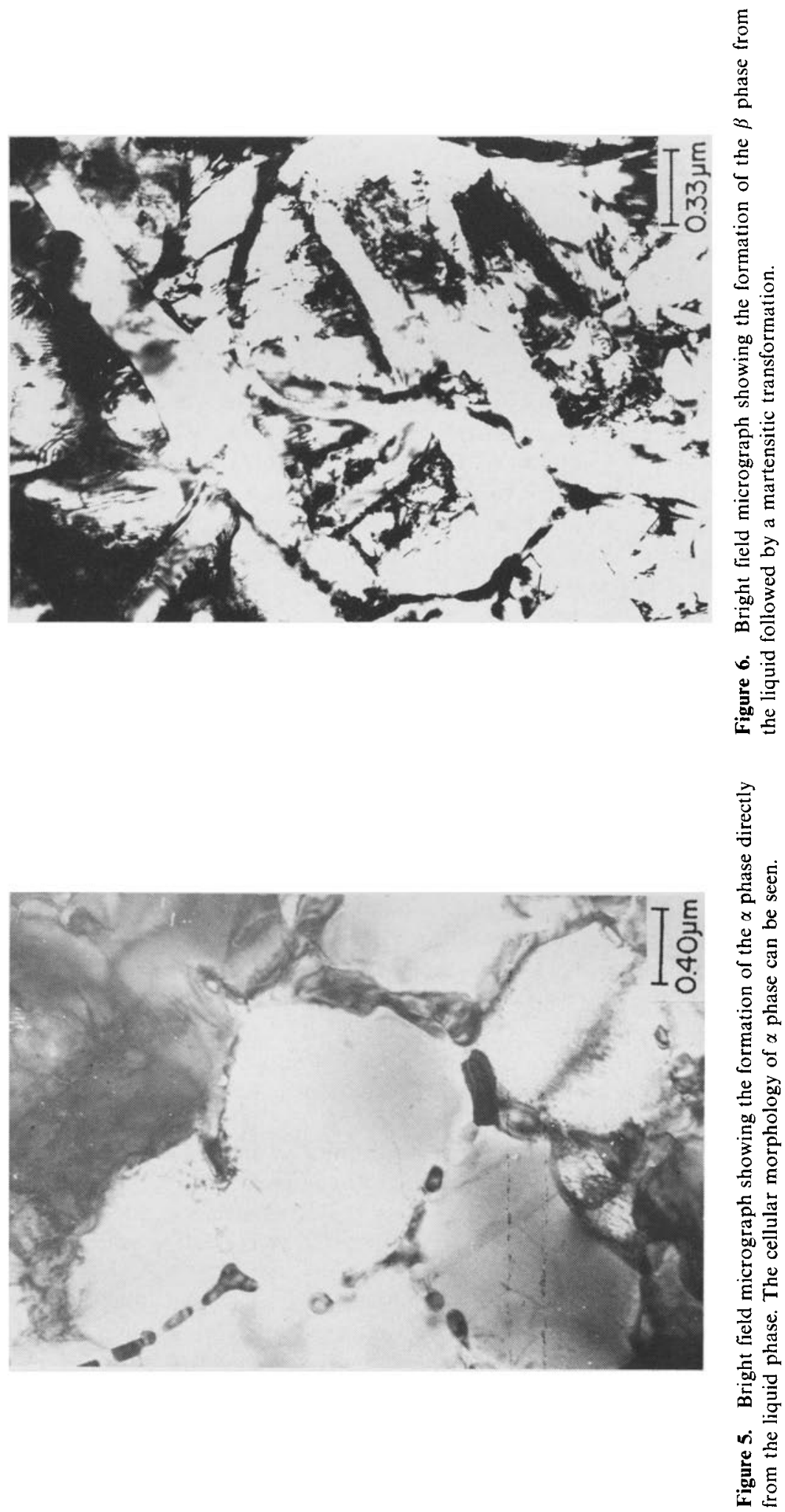


\section{Acknowledgements}

It is pleasure to acknowledge the benefit of several discussions the authors had with Dr P Mukhopadhyay, Shri E G Baburaj, Shri R T Savalia and Shri R Tewari.

\section{References}

Aptekar I L and Kamenetskaya D S 1962 Fiz. Met. Metalloved. 14358

Baker J C and Chan J W 1971 in Solidification (Metals Park, Ohio: American Society for Metals) p. 23

Banerjee S and Cantor B 1979 Proc. Int. Conf. on martensitic transformation, Boston, p. 195

Banerjee S and Cahn R W 1983 Acta Metall. Mater. 311721

Boettinger W J 1982 Proc. 4th Int. Conf. on rapidly quenched metals, Sendai 1981, (eds) T Masumoto and K Suzuki (Sendai: Japan Institute of Metals) p. 99

Burleigh T D, Jones E R C and Latanision R M 1985 Proc. 5th Int. Conf. on rapidly quenched metals, Wuizburg, 1984 (eds) S Steeb and H Warlimont (Amsterdam: North Holland) vol. I, p. 1457

Buschow K H J 1983 Acta Metall. Mater. 31155

Buschow K H J 1984 J. Phys. F. Metal Phys. 14593

Buschow K H J and Beekmans N M 1979 Phys. Rev. B19 3843

Calka A, Radlinski A P and Luther-Davies B 1987 Scr. Metall. 211445

Chen H S 1976 Acta Metall. Mater. 24153

Chen H S 1980 Rep. Prog. Phys. 43355

Chen H S and Krause J T 1977 Scr. Metall. 11761

Davies H A 1976 Phys. Chem. Glasses 17159

Dey G K 1988 Rapid solidification of zirconium alloys, Ph. D. Thesis, Banaras Hindu University, Varanasi

Dey G K and Banerjee S 1985a Mater. Sci. Engg. 73187

Dey G K and Banerjee S 1985b Proc. 5th Int. Conf. on rapidly quenched metals, Wuizburg, 1984, (eds) S Steeb and H Warlimont (Amsterdam: North Holland) Vol. I, p. 67

Dey G K and Banerjee S 1985c Mater. Sci. Eng. 76127

Dey G K and Banerjee S 1985d J. Mater. Sci. 202913

Dey G K, Savalia R T, Baburaj E G and Banerjee $S$ (unpublished work)

Dey G K, Baburaj E G and Banerjee S 1986 J. Mater. Sci. 21117

Dey G K, Baburaj E G, Banerjee S and Ramachandra Rao P 1987 in Metallic and semiconducting glasses, (ed.) A K Bhatnagar (Switzerland: Key Engineering Materials, Trans. Tech Publishers) Vol. II, p. 329

Dey G K, Savalia R T, Sharma S K and Kulkarni S K 1989 Corr. Sci. 29823

Dey G K, Savalia R T, Baburaj E G and Banerjee S 1990 Proc. Int. Conf. on rapid solidification processing and technology, ICMS 1989, (eds) O N Mohanty and C S Sivaramakrishnan (Switzerland: Key Engg. Mater. Trans. Tech. Publishers) p. 135

Donovan P E and Stobbs N M 1980 J. Microsc. 11939

Douglass D L 1971 in The metallurgy of zirconium, (Vienna: Int. Atomic Energy Agency) p. 229

Drehman A J and Greer A L 1984 Acta Metall. Mater. 32323

Ghosh G, Chandrashekaran M and Delaey L 1991 Acta Metall. Mater. 39 37, 929

Greer A L 1985 E.P.R.I. Acta Metall. Mater. workshop on amorphous and semiconductors, San Diego, California (Pergamon Press) p. 29

Harmelin M, Calvayrac R, Ovivy A, Bigot J, Burnier P and Fayard M 1984 J. Non-Cryst. Solids 61/62 931

Katgerman L 1983 J. Mater. Sci. Lett. 2444

Kavesh S 1978 in Metallic glasses, (eds) J J Gilman and H J Leamy (Metals Park, Ohio: ASM) p. 36

Kelton K F. Greer A L and Thompson C V 1983 J. Chem. Phys. 796261

Kelton K F and Greer A L 1986 J. Non-Cryst. Solids 79295

Kuan T S and Sass S L 1976 Acta Metall. Mater. 241053

Marcus M and Turnbull D 1976 Mater. Sci. Engg. 23211

Massalski T B 1975 Mater. Sci. Engg. 25119

Massalski T B 1982 Proc. 4th Int. Conf. on rapidly quenched metals, Sendai 1981, (eds) T Masumoto and K Suzuki (Sendai: Japan Inst. Metals) p. 203

Nagel S R and Tauc J 1975 Phys. Rev. Lett. 35380

Naka M, Hashiimoto K and Masumoto T 1987 J. Non-Cryst. Solids 28403 
Sethi V K, Gibala R and Hevex A H 1978 Scr. Metall. 12207

Tanner L E 1980 Acta Metall. Mater. 281805

Thompson C V, Greer A L and Spaepan F 1983 Acta Metall. Mater. 311883

Turnbull D 1969 Contemp. Phys. 10473

Turn J C and Latanision R M 1983 Corrosion 39271

Ulhmann D R 1974 J. Non-Cryst. Solids 1615

Walter J L 1981 Mater. Sci. Engg. 50137

Zielinski P G, Ostatek J, Kijek M and Matyja H 1978 in Rapidly quenched metals, (ed.) B Cantor, (London: The Metals Society) Vol. 1, p. 337 